\title{
Effect of freezing on the performance of EMAS in different water absorption
}

\author{
MiaomiaoFan ${ }^{\mathrm{a}}$, HongbinYu ${ }^{\mathrm{b}}$ \\ School of Mechanical Engineering, Tianjin Polytechnic University, Tianjin 300387, China \\ aFmm_1122@163.com, 'bhongbinyu@aliyun.com
}

Keywords:EMAS; aircraft; temperature; humidity; freezing.

\begin{abstract}
Engineered Material Arresting System (EMAS) is a new type of soft ground arresting system that can safely arrest the overrun aircraft in an allowed distance without injuring aircraft passengers and damaging aircraft landing gear. When exposed in the outdoor, the temperature and humidity will have a great impact on the performance of EMAS core layer which is a kind of foam concrete. In this paper, dynamic test and microscopic observation were conducted to find out the effect of freezing on the EMAS core layer in different water absorption.
\end{abstract}

\section{Introduction}

Engineered material arresting system, EMAS, which is an effective block to avoid the aircraft of running out of the runway, has played an increasingly important role. As a means of safety guarantee for the aircraft and passengers, EMAS has been widely used at home and abroad. EMAS is a new type of soft ground arresting system, which is paved at the end of the runway. The blocking effect of EMAS core layer on the aircraft determines the performance of the whole EMAS.

EMAS core layer is kind of foam concrete which is composed of cementitious mortar surrounding disconnected random air bubbles, with the air typically occupying more than $50 \%$ of the volume. The air bubbles are a result of gas formed within the mortar or foam introduced into the mortar mixture ${ }^{[1]}$.

As has been exposed in the outdoor, environment temperature, humidity and other factors have a great impact on the performance of EMAS. The core layer of EMAS consists of the foam concrete, while the water in the foam concrete is mainly free water or absorbed water, rather than the capillary water. The space of the porous concrete is much larger than the ordinary concrete, so when contact with the water in the same time, the saturation and the depth of the foam concrete is much larger than the ordinary concrete, which results in a much higher water content saturation region and relatively dry interior region. Consequently, when the temperature changes, the volume of water in the foam concrete will be larger, which will lead to the change of the performance of foamed concrete ${ }^{[2]}$. Research on the influence of environment on the performance of foamed concrete preparation is therefore recently more and more getting its attention than ever before.

\section{Materials and experimental procedure}

Materials preparation. The experiment use EMAS core layer materials in the same batch, density, height and same maintenance environment. EMAS core layer is a foaming agent which is added to the made of cement, aggregate, lightly doped synthetic material, additive and water made of slurry and the mixed stirring, pouring molding and natural or steam curing made of porous lightweight foam concrete. The foam concrete is produced by adding foaming agent into slurries mixed with cement, water, aggregate, admixture, etc, quickly without stopping mixing. The mixture slurry is then discharged out of the mixer and placed into moulds immediately after the foaming agent starts to foam and its volume begins to expand. EMAS specimen is thus prepared after sealed curing in mould for $24 \mathrm{~h}$, followed by sequential natural or steam curing. The preparation process of the specimen is as illustrated in Fig. ${ }^{[3]}$. 


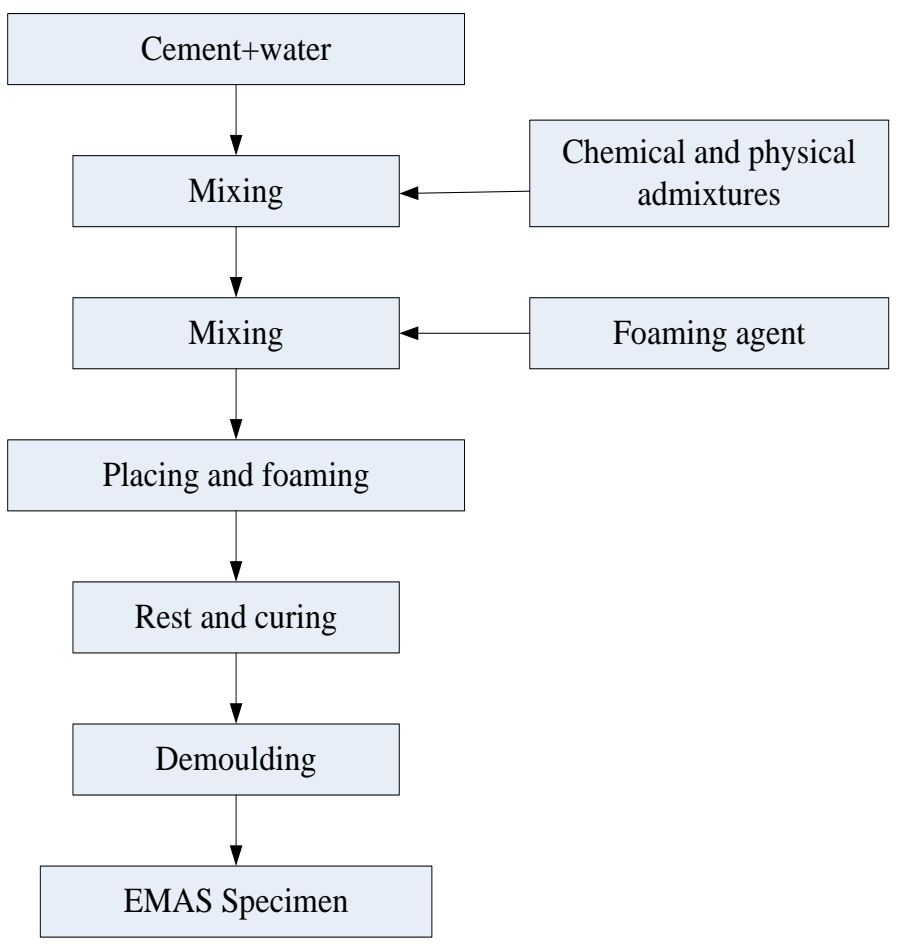

Fig.1 Schematic diagram for the procedure of EMAS preparation

\section{Experimental procedure}

\subsection{Previous preparation}

As a result of paving in airport, rain, humidity, wind will cause changes in the degree of water absorption of the EMAS. For the test procedures, the EMAS specimens were removed from their molds and cured at $23{ }^{\circ} \mathrm{C}$ and $97 \%$ relative humidity for 28 days. After 28 days, the specimen was weighed immediately after removal from the curing chamber and subjected to a saturation procedure $^{[4]}$. Each specimen is a cube with a size of $100 \times 100 \times 100$. The saturation procedure consisted of submerging 6 small specimens under $2 \mathrm{~cm}$ of water at $15^{\circ} \mathrm{C}$ continued for $15 \mathrm{~min}, 30 \mathrm{~min}$, 45min, 60min, 75min and 90min, therefore the specimens will obtain different water absorption. Labeled the 4 small specimens as M1, M2, M3, M4, M5 and M6 in turn. After the saturation procedure, the weight of each specimen was determined by drying the excess water from the surface and weighing. Freezing process was performed following the curing and saturation procedure which consists of freezing the specimens in air at a temperature of $-18^{\circ} \mathrm{C}$.

\subsection{Microstructure observation}

On the basis of the preparations prepared above, observe the microstructure of 4 specimens before and after freezing. The analysis of the influence of freezing on specimens will be conducted following according to the specimens' microstructure changes.

\subsection{The dynamic test platform construction}

The role of EMAS played is to avoid the plane running out of the runway when the plane can't stop as usual; hence the critical performance of EMAS is compressive strength. In order to examine the compressive strength of EMAS, the dynamic test platform needs to set up.

Fig. 2 shows the component of the platform. It consists of a direct-current motor, a pressure sensor with a range of $0-10 \mathrm{~kg}$ and a squeeze head. The motor is above the pressure senor, the following is a squeeze head. The specimens are placed under the experimental platform, and the pressure head is controlled by the motor ${ }^{[6]}$. In the experiment, the press head moves down gradually and presses the specimens until they are crushed. The output signal of the pressure senor is voltage signal. During this process, the pressure senor's output terminal is connected to a data acquisition card to observe the change of output signal in the form of output variation curve. 


\section{Results and discussion}

\subsection{Microscopic phenomenon}

For the 6 pieces of EMAS specimens, the microscopic observation was taken before and after freezing. The microscopic appearance before freezing is shown in Fig.2.

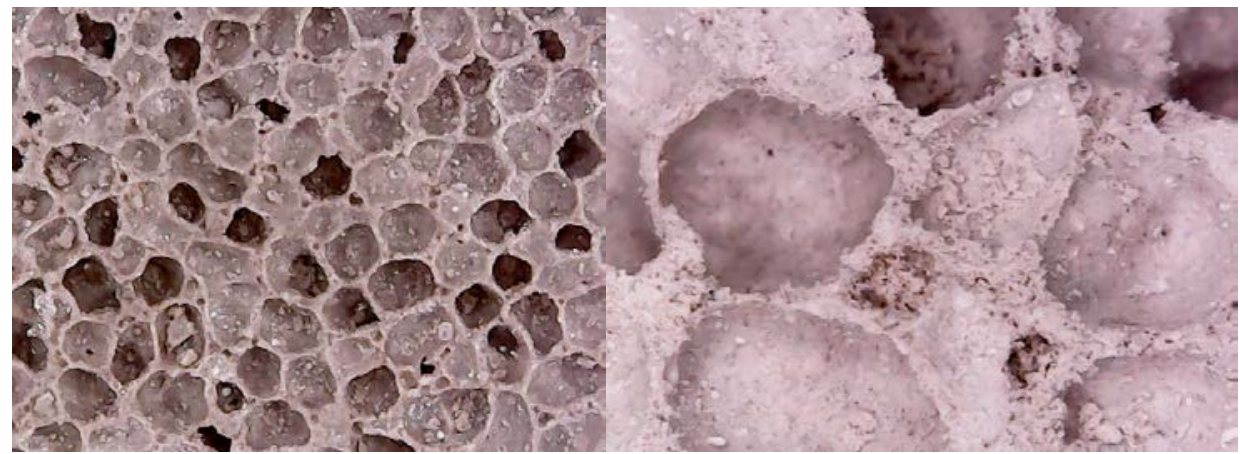

Fig.2 the microscopic appearance before freezing

As shown in Fig.2, the pores in the EMAS specimens are uniformly continuous in initial circumstances. This event illustrates the integrated and strong performance of the EMAS core layer. The performance of the specimens after freezing in different water absorption can be expressed in Fig.3.
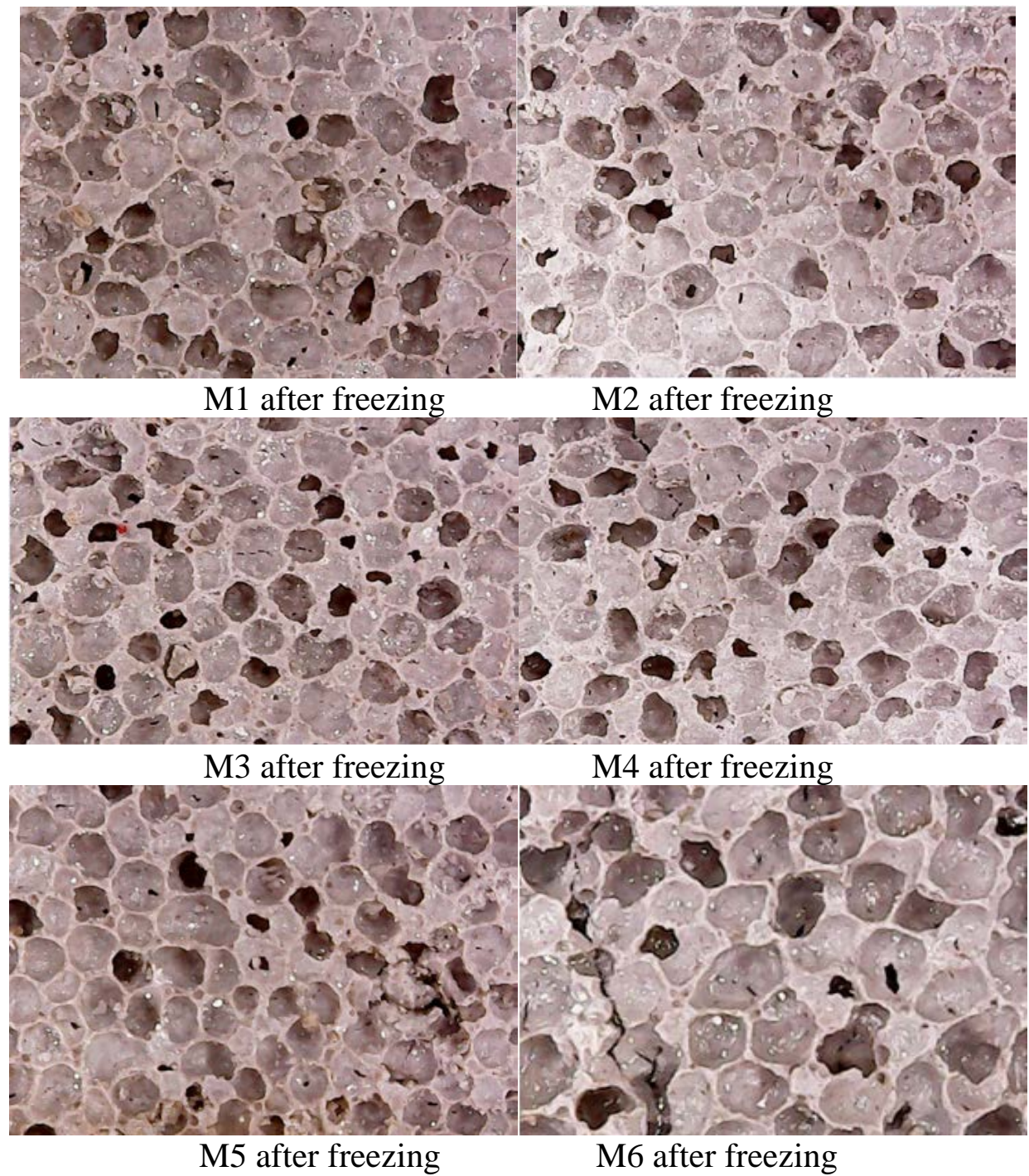

Fig.3 the microscopic appearance after freezing 
When a concrete structure is exposed to the freezing conditions, aqueous solution in the capillary pores transforms into ice and expands about $9 \%$ of its volume. Due to the volume expansion, unfrozen water tends to move into any available adjacent voids and eventually creates hydraulic pressure. When expansive force overcomes the tensile strength of the concrete or mortar, microcracks are generated and propagated to the cement matrix ${ }^{[2]}$. It can be seen through the microscopic maps of the above, there is almost no changes of M1. An extremely tiny crack can be observed in the middle of M2. Along with the increase of immersing time in water, the specimens' structures have been changed also after freezing. The tiny crack increases in M3, meanwhile the crack in M4 is a little clear then M3. The surface of M5 becomes rougher and looser in a way, in addition, the specimen spalls a little. After 90min immersing in water, the absorption of M6 is maximum, which leads to a relatively large crack as shown in the picture above.

\subsection{Dynamic test results}

The output of the pressure sensor is illustrated as voltage, so the value of the output voltage indicates the change of stress on specimens. There are 6 curves synthesized through the data collected by the data acquisition card. The curves are shown as Fig.4.

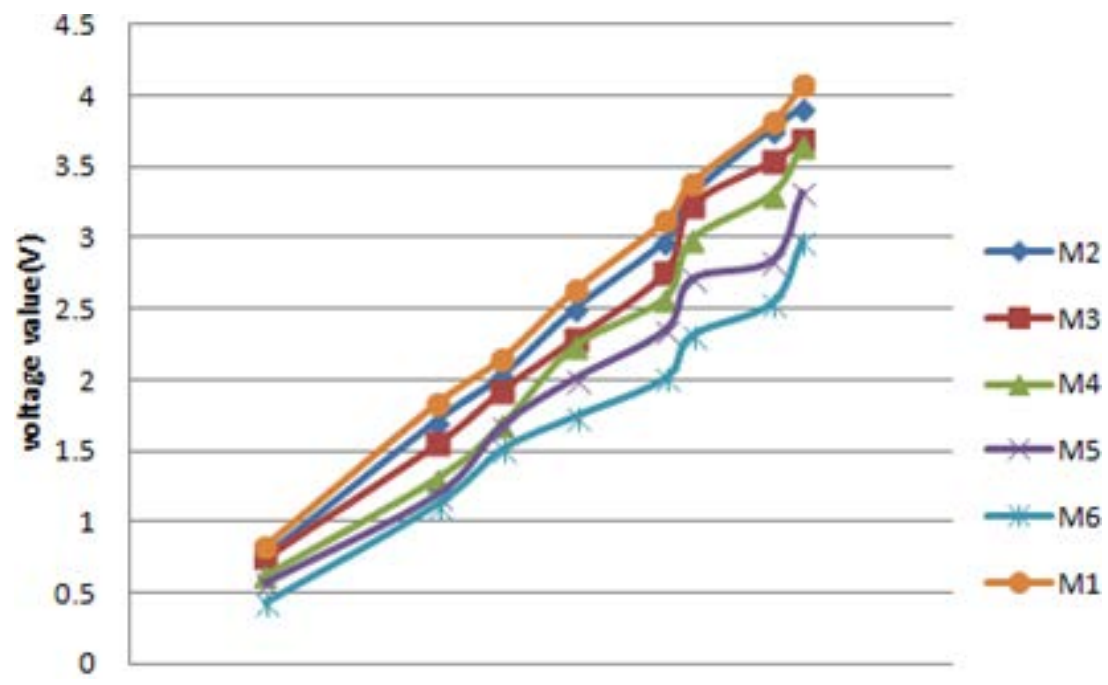

Fig.4 the change of voltage value

The curves above shows that the voltage value gradually increase when pressure head drops down until the specimens break apart, which indicates that the force required gradually increased. The force required declined from M1 to M6. From this phenomenon it can be calculated that the compressive capacity of the specimens under freezing conditions will decrease a little with the increase of water absorption $^{[5]}$.

\section{Summary and conclusions}

The results of this study show that depth of water absorption were found to relate with the freeze durability. When water absorption increases, the compressive capacity of EMAS core layer decreases. The results can provide some help for the pavement and application of EMAS in the airport. However, the test sample used in this research is little which may cause the test result is not convincing enough. More influence factors of the environment should be considered in the following researches.

\section{Acknowledgement}

The work described in this paper is financially supported by the Civil Aviation Joint Research foundation under grant number U1333129. 


\section{References}

[1] Paul J. Tikalsky, James Pospisil, William MacDonaldc. A method for assessment of the freeze-thaw resistance of preformed foam cellular concrete[J]. Cement and Concrete Research. Vol.34 (2004) p. 889-893.

[2] Ali Allahverdi, MohammadMahdi Bahri Rasht Abadi, KhandakerM. AnwarHossain, et al. Resistance of chemically-activated high phosphorous slag content cement against freeze-thaw cycles[J]. Cold Regions Science and Technology. Vol. 103 (2014) p. 107-114.

[3] Pan Zhihua, Li Hengzhi, Liu Weiqing. Preparation and characterization of super low density foamed concrete from Portland cement and admixtures[J]. Construction and Building Materials. Vol. 72 (2014) p. 256-261.

[4] Daniel E. Ramirez-Arreola, Cesar Sedano-de la Rosa, Nadia B. Haro-Mares. Compressive strength study of cement mortars lightened with foamed HDPE nanocomposites[J]. Materials and Design. Vol. 74 (2015) p. 119-124.

[5] D.A. Silva, A.M. Betioli, P.J.P. Gleize, et al. Degradation of recycled PET fibres in Portland cement-based materials[J]. Cem.Concr. Res. Vol. 35 (2005) p. 1741-1746.

[6] Mydin Md Azree Othuman, Wang YC. Mechanical properties of foamed concrete exposed to high temperatures[J]. Construct Build Matererial. Vol. 26(2012) p. 638-54. 